\title{
A Determination Method of Optimal Customization Degree of Logistics Service Supply Chain with Mass Customization Service
}

\author{
Weihua Liu, Qian Wang, Donglei Zhu, and Yang Liu \\ College of Management \& Economics, Tianjin University, Tianjin 300072, China \\ Correspondence should be addressed to Weihua Liu; lwhliu888@163.com
}

Received 10 April 2014; Accepted 20 May 2014; Published 23 June 2014

Academic Editor: Xiang Li

Copyright ( 2014 Weihua Liu et al. This is an open access article distributed under the Creative Commons Attribution License, which permits unrestricted use, distribution, and reproduction in any medium, provided the original work is properly cited.

\begin{abstract}
Customization degree is a very important field of mass customization. Its improvement could enhance customer satisfaction and further increase customer demand while correspondingly it will increase service price and decrease customer satisfaction and demand. Therefore this paper discusses how to deal with such issues in logistics service supply chain (LSSC) with a logistics service integrator (LSI) and a customer. With the establishment of customer demand function for logistics services and profit functions of the LSI and the customer, three different decision modes are proposed (i.e., customization degree dominated by LSI, customization degree dominated by customer, and customization degree decided by concentrated supply chain); many interesting findings are achieved. Firstly, to achieve customization cooperation between LSI and customer, measures should be taken to make the unit increase cost of the customized logistics services lower than a certain value. Secondly, there are differences between the optimal customization degree dominated by LSI and that dominated by customer. And in both cases, the dominator could realize more profit than the follower. Thirdly, with the profit secondary distribution strategy, the modified decentralized decision mode could accomplish the maximum profit achieved in centralized decision mode and meanwhile get the optimal customization degree.
\end{abstract}

\section{Introduction}

Currently, customer requirements for specialized and customized logistics services have increased. So, many logistics enterprises begin to explore the way that can meet the specialized service [1], change the logistics service mode, and even attempt to provide mass customization logistics service (MCLS) instead of only mass logistics service. In the MCLS environment, many logistics enterprises spontaneously form a logistics service supply chain (LSSC) through unions and integrations to meet customized demand and offer large-scale services [2,3]. In a logistics service supply chain (LSSC) [3], a logistics service integrator (LSI) provides customized logistics services by integrating the service capacities of multiple functional logistics service providers (FLSPs); the LSI and the FLSPs constitute a logistics service supply chain (LSSC). For instance, Baogong Logistics Company, one of the largest LSI in China, integrates more than 500 storage companies, more than 1,200 highway transportation companies, and over 500 manual loading and unloading companies as its FLSPs and then accomplishes the integrated logistics services for its customers such as Procter \& Gamble and Philips.

In mass customization service, the customization degree is a very important parameter which will directly affect the cooperation between the LSI and the customer. From the customer's perspective, the improvement of customization degree can enhance customer satisfaction and then increase the customer demand. However, the customization degree also will lead to service price rising, which can result in the reduction of customer satisfaction and demand. And from the LSI's perspective [4], although higher customization degree can get more customers demand, it also increases the cost of enterprise services and does not necessarily get higher profits. Obviously, from the practical level, coordinating the customization degree of service between the LSI and the customer reasonably is a significant precondition for them to cooperate. This is also the practical motivation for the research.

This paper is also motivated by the existing literature shortages. From the literature research, on the one hand, most 
of the research on mass customization degree is for qualitative analysis (e.g., da Silveira et al. [5]; Bardakci and Whitelock [6]; Cavusoglu et al. [7]). Though some scholars have turned to quantitative research (e.g., Lian and Ji [8]; Sami Spahi [9]; Xu et al. [10]), generally the conclusion is about the relationship between customization degree and a certain influence factor which does not give the exact customization degree. On the other hand, most of the study on mass customization degree is about manufacturing supply chain, and studying on LSSC in mass customization is still very few. Moreover, the existing decision research about LSSC in mass customization [1114] does not consider the problem of optimal customization degree. Therefore, this paper will focus on the issue of customization degree in mass customization service. From the perspective of maximizing profit of the LSI and the customer, the optimal service customization degree could be determined.

The organizational structure of this paper is shown as follows. Section 2 reviews the related contents about mass customization production mode, customization degree, and mass customization service mode. In Section 3, with customer demand function for logistics services established, the LSI and the customer's profit function are proposed. Section 4 illustrates three different decision models about customization degree. And how the profit of the LSI or customer as well as the overall supply chain change is discussed along with the customization degree in different decision models. Then the decision model of the optimal customization degree based on the profits secondary distribution strategy is proposed. In Section 5, the numerical analysis is carried out within Matlab 8.0, and it verifies these conclusions made in this paper. Section 6 summarizes main conclusions and points out future research prospects.

\section{Literature Review}

At present, the research on mass customization degree mainly focuses on manufacturing supply chain, while the research on service supply chain, especially logistics service supply chain, is still relatively lacking. Hence, according to the research contents of this paper, the literature review section mainly includes two aspects. (1) Summarize the related research results about Mass customization production mode and customization degree; (2) Review the literatures of mass customization service mode.

\subsection{Mass Customization Production Mode and Customization} Degree. Since the concept of mass customization production mode was proposed, many enterprises have implemented this advanced mode of production. Mass customization has become a key competitive advantage for many companies, and many enterprises have benefited from the production mode [15, 16], such as automobile enterprises, clothing enterprises, and computer manufacturing enterprises. Many scholars have done much exploration about the theory of mass customization in different areas. Currently, the research field of mass customization mainly concentrated in the food industry [17], electronic industry [18], large-scale engineering products [19], mobile phones [20], and other production areas. Although the study of mass customization has obtained many achievements, according to the research of Fogliatto et al. [21] who has reviewed the related literatures of MC over the past decade, there are many problems about MC still not solved, such as supply chain coordination, quality control, and rapid manufacturing are still the research field of MC for the future.

In mass customization, the coordination of customization degree is very important. The implementation of mass customization will cause the price of customized products increased [6]. They find that customization is not optimal when the cost of soliciting customer preference information is sufficiently high [7]. Therefore, it is particularly important to determine an appropriate customization degree. To determine an appropriate customization degree, customer demand and enterprise's production capacity should be analyzed scientifically [5]. As the research of mass customization degree gets more attention, the research of customization degree is gradually changing from qualitative research to quantitative research. Liang and Zhou [22] from the perspective of customer satisfaction and enterprise cost, discussed how enterprise determines the customization degree reasonably, when the enterprise's ability of MC is certain. $\mathrm{Li}$ and Cheng [23] analyzed the optimization problem of customization degree from two aspects, which are product family functional of MC and customer satisfaction. Lian and Ji [8] and Zhou et al. [4] analyzed the customization degree of mass customized products and discussed the relationship between the customization degree and the market demand and the manufacturer's profits. Sami Spahi [9] defined a customization degree of products from the perspective of product structure and established an optimization model to determine the optimal customization degree that can meet organizational goals. Using the combination analysis method, $\mathrm{Xu}$ et al. [10] established a measurement model of product customization degree which is based on the attribute significance. At the point of view of dynamic customization degree, Wang [24] analyzed the demand and supplied uncertain problems. He also did a further research [25] on different industry implementing VMI strategy cost model and a quantitative model for the customization degree.

While the existing researches on customization degree are reviewed, it is found that most of them are about qualitative analysis. Though some scholars have turned to quantitative research, generally the conclusion is about a relationship between customization degree and a certain influence factor which does not give the exact expression of customization degree.

2.2. Mass Customization Service Mode. In the service industry, especially logistics services industry, with large-scale logistics service turned to mass customization logistics service, some scholars have begun to research mass customization service problems. But the literatures still lack research on the optimal customization degree of service. For example, van Hoek [26] analyzed the challenges to the third party logistics service providers (LSP) which is put forward by MC and 
proposed a logistics services framework for the delay of MC. Chandra and Kamrani [11] discussed the impact of the MC demand on the MC strategy and logistics service in supply chain. On the basis of Koste and Malhotra's research [27], Lummus et al. [28] established a supply chain service model which can meet the demand of customers personalized, from the perspective of MC. Liu et al. [12] studied the issue of time schedule in mass customization logistics service mode. Liu et al. [13] also studied the issue of order allocation of logistics service supply chain with mass customization logistics service. In addition, the decision problem of customer order decoupling point (CODP) with mass customization service is also beginning to be studied [14].

The literature review indicates that now the study of the optimal customization degree is relatively lack in mass customization service. Although scholars have focused on the optimal customization degree of production, these studies have focused on the relationship between customization degree and a certain influence factor which does not give the exact customization degree.

Therefore, for the deficiency of previous literatures, this paper will focus on the coordinated issue of customization degree in mass customization service. And from the perspective of maximizing profit of the LSI and the customer, the optimal service customization degree would be determined.

\section{Model Building}

This part mainly studies model building. In Section 3.1, the problem description is presented and the model assumptions and variables are given. Then, in Section 3.2, the demand function of the customer for logistics services is built, and on this basis, the LSI and the customer's profit function are provided.

3.1. Problem Description. In a LSSC with mass customization service, the coordination issue of customization degree between a LSI and a customer (e.g., a certain manufacturing enterprise) would be discussed. The LSI can provide largescale service and customized service to customer, and the customer's demand consists of a certain customization degree. When the LSI receives the order of customer, he will analyze the customization degree and then provide the corresponding logistics services to the customer.

The customer who has chosen mass customization service improved the market reaction speed, compared with the merchants that did not choose mass customization service. Therefore, it will increase product customers and sales volume of product and greatly improve the customer satisfaction. Figure 1 shows the model of LSSC with mass customization service.

Table 1 shows the notations of the model. Other assumptions of the model are as follows.

(1) In fact, when the LSI I received the customer's orders, he will deliver them to the FLSP $S$ who can provide Large-scale service and customized service. It is assumed that the capacity of the FLSP $S$ could always meet the demand of customer, and its capacity

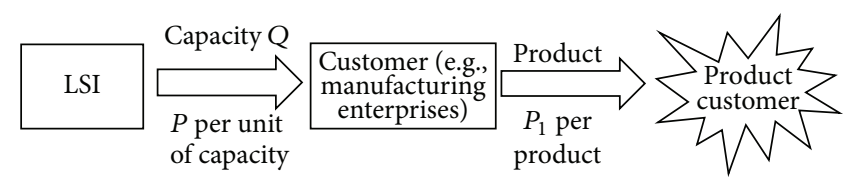

FIGURE 1: Logistics service supply chain (LSSC) model.

could never be insufficient. To simplify the analysis, we regard the FLSP $S$ as a branch of the LSI $I$, and the LSI can provide mass customization to customer directly, when he received the customer's orders.

(2) It is assumed that the customization degree is $\gamma=$ $n / m$ ( $m$ represents the total link number of service that customer demand, $n$ represents the link number of customized service that the LSI provides to the customer, $m \geq n)[4]$, so $\gamma \in[0,1]$. When $\gamma=0$, it represents the LSI provides complete large-scale service to customer; when $0<\gamma<1$, it represents the LSI provides mass customization service to customer; when $\gamma=1$, it represents the LSI provides complete customization service to customer.

(3) The LSI's cost includes the cost of large-scale service and the cost of customization service. When the customer accepts the mass customization service, the production cost of the customer's product $P_{0}$ and the unit price of the product $P_{1}$ are all constant.

(4) Generally, the unit cost of customization service is higher than that of large scale service. Therefore, if the cost of the customization service of the LSI is too high, it will result in an excessive price to customer, which will also decrease customer demand. The profit of the LSI may be decreased. So it is assumed that the increased cost, compared with complete large-scale logistics service, should be shared with the customer and the LSI together; the proportion, respectively, is $\beta$ and $1-\beta$.

\subsection{Model Building}

3.2.1. The Demand of Customer for Logistics Service. In the MCLS, the demand of customer will increase with the increase of customization degree, but with the increase of customized price, it will reduce. The demand function of economics $Q=a-b P$ just defines the relationship between the demand and the price. Considering that with the increase of customization degree, the demand of customer also will increase, so the customization degree factor $t$ is introduced and set as $t=\gamma /(1-\gamma)$. Therefore, referring to the above demand function, the total logistics service demand function of customer could be shown as:

$$
Q=a-b P+t Q_{0}=a-b P+\frac{\gamma}{1-\gamma} Q_{0} .
$$

In (1), $a, b$ are constants greater than $0, b P$ represents the decreased demand that is just caused by the price, and $(\gamma /(1-$ $\gamma)) Q_{0}$ represents the decreased demand that is just caused 
TABLE 1: Model notations.

\begin{tabular}{|c|c|}
\hline Notations & Description \\
\hline$\gamma$ & Customization degree \\
\hline$t$ & Customization degree factor \\
\hline$a$ & Potential demand of customer \\
\hline$b$ & The price sensitive parameter of customer \\
\hline$\mu$ & The change rate of demand \\
\hline$C_{1}$ & $\begin{array}{l}\text { The unit cost of complete large-scale } \\
\text { logistics service that the LSI provides to } \\
\text { customer }\end{array}$ \\
\hline$C_{2}$ & $\begin{array}{l}\text { The unit increased cost, compared with } \\
\text { complete large-scale logistics service that the } \\
\text { LSI provides to customer }\end{array}$ \\
\hline C & $\begin{array}{l}\text { The total unit cost of MCLS that the LSI } \\
\text { provides to customer }\end{array}$ \\
\hline$P$ & $\begin{array}{l}\text { The unit price of MCLS that the LSI } \\
\text { provides to customer }\end{array}$ \\
\hline$P_{0}$ & $\begin{array}{l}\text { Besides the cost of MCLS, the production } \\
\text { cost of the customer's products }\end{array}$ \\
\hline$P_{1}$ & $\begin{array}{l}\text { The unit price of the product, when the } \\
\text { customer accepted MCLS }\end{array}$ \\
\hline Q & The total demand of customer for MCLS \\
\hline$Q_{0}$ & $\begin{array}{l}\text { The increased demand caused by } \\
\text { customization }\end{array}$ \\
\hline$Q_{1}$ & $\begin{array}{l}\text { The demand of customer when the LSI } \\
\text { provides complete large-scale logistics } \\
\text { service to customer }\end{array}$ \\
\hline$\omega$ & $\begin{array}{l}\text { Marginal profit ratio that the LSI provides } \\
\text { complete large-scale logistics service to } \\
\text { customer }\end{array}$ \\
\hline$\beta$ & $\begin{array}{l}\text { The proportion that borne by customer for } \\
\text { increased cost of customization }\end{array}$ \\
\hline$\pi_{1}$ & The total profit of LSI \\
\hline$\pi_{2}$ & The total profit of customer \\
\hline$\pi_{T}$ & The total profit of LSI and customer \\
\hline$\pi_{1}^{\prime}$ & The optimal total profit of LSI \\
\hline$\pi_{2}^{\prime}$ & The optimal total profit of customer \\
\hline$\pi_{T}^{\prime}$ & The optimal total profit of LSI and customer \\
\hline$\Delta \pi_{1}$ & $\begin{array}{l}\text { The profit-loss when customization degree } \\
\text { decided by concentrated supply chain, } \\
\text { compared with customization degree } \\
\text { dominated by LSI }\end{array}$ \\
\hline$\Delta \pi_{2}$ & $\begin{array}{l}\text { The profit-loss when customization degree } \\
\text { decided by concentrated supply chain, } \\
\text { compared with customization degree } \\
\text { dominated by customer }\end{array}$ \\
\hline$\pi_{\text {final } 1}$ & $\begin{array}{l}\text { The final profit of LSI after profits secondary } \\
\text { distribution }\end{array}$ \\
\hline$\pi_{\text {final } 2}$ & $\begin{array}{l}\text { The final profit of customer after profits } \\
\text { secondary distribution }\end{array}$ \\
\hline$M_{1}$ & $\begin{array}{l}\text { The profit paid to LSI in profits secondary } \\
\text { distribution }\end{array}$ \\
\hline$M_{2}$ & $\begin{array}{l}\text { The profit paid to customer in profits } \\
\text { secondary distribution }\end{array}$ \\
\hline
\end{tabular}

TABle 1: Continued.

\begin{tabular}{ll}
\hline Notations & Description \\
\hline$\pi_{1}^{\text {case } i}(i=\mathrm{A}, \mathrm{B}, \mathrm{C})$ & $\begin{array}{l}\text { The profit of LSI in the three different } \\
\text { decision modes of A, B, C }\end{array}$ \\
$\pi_{2}^{\text {case } i}(i=\mathrm{A}, \mathrm{B}, \mathrm{C})$ & $\begin{array}{l}\text { The profit of customer in the three different } \\
\text { decision modes of A, B, C }\end{array}$ \\
$\pi_{T}^{\text {case } i}(i=\mathrm{A}, \mathrm{B}, \mathrm{C})$ & $\begin{array}{l}\text { The total profit of LSI and customer in the } \\
\text { three different decision modes of A, B, C } \\
\text { The customization degree factor that can } \\
\text { make the profit of the LSI is maximum, } \\
\text { when the customization degree dominated } \\
\text { by LSI } \\
\text { The customization degree factor that can } \\
\text { make the profit of the customer is } \\
\text { maximum, when the customization degree } \\
\text { dominated by customer } \\
\text { The customization degree factor that can } \\
\text { make the profit of the LSI and the customer } \\
\text { is maximum, when the customization } \\
\text { degree decided by concentrated supply chain }\end{array}$ \\
$t^{\text {case B }}$ &
\end{tabular}

by customization degree. When the LSI provides complete large-scale logistics service to the customer, the demand of customer $Q_{1}$ should not be less than 0 , namely, when $\gamma=0$, the equation of customer's demand is shown in the following:

$$
Q_{1}=a-b P \geq 0 .
$$

When providing MCLS to customer, the LSI's total cost mainly includes the cost of large-scale logistics $C_{1}$ and the cost of customization logistics service $t C_{2}$, as shown in the following:

$$
C=C_{1}+t C_{2}=C_{1}+\frac{\gamma}{1-\gamma} C_{2} .
$$

And in this equation, $C_{2}$ is the unit increased cost that compared with complete large-scale logistics service that the LSI provides to customer. $t=\gamma /(1-\gamma)$ is the customization degree factor.

According to the assumption (4), the increased cost, compared with complete large-scale logistics service, should be borne by the customer and the LSI corporately, and the proportion, respectively, is $\beta$ and $1-\beta$. Therefore, the unit price of MCLS that the LSI provides to customer $P$ includes two parts, one is large-scale logistics service's cost $C_{1}(1+\omega)$ which considers the LSI's marginal profit, and the other is Customized logistics service costs $\beta t C_{2}$, which considers the compensation of customized service. So $P$ can be expressed as follows:

$$
P=C_{1}(1+\omega)+\beta t C_{2}=C_{1}(1+\omega)+\beta \frac{\gamma}{1-\gamma} C_{2}
$$

With (4) substituted into (1), the total demand of customer for logistics service with MCLS is presented as follows:

$$
\begin{aligned}
Q & =a-b\left[C_{1}(1+\omega)+\beta t C_{2}\right]+t Q_{0} \\
& =a-b\left[C_{1}(1+\omega)+\beta \frac{\gamma}{1-\gamma} C_{2}\right]+\frac{\gamma}{1-\gamma} Q_{0} .
\end{aligned}
$$


To further study the impact of customized services on the demand of customer, take the first-order derivative of $Q$ versus $t$

$$
\frac{\partial Q}{\partial t}=Q_{0}-b C_{2} \beta
$$

Equation (6) represents the change degree of customer's demand with the change of customization degree factor, which could be defined as $\mu$, that is, the change rate of demand caused by customization, which is seen in the following:

$$
\mu=Q_{0}-b C_{2} \beta .
$$

Theorem 1. The total demand of customer for logistics service is influenced by both the price and the customization degree. And it will increase with the increase of customization degree, but with the increase of price, it will decrease.

The state of Theorem 1 is obvious. It can be obtained from the former analysis, and in the article of Zhou et al. [4], the similar state can be found.

Corollary 2. When the increased demand caused by the increasing customization degree is higher than the decreased demand caused by the increasing price, the change rate of demand will be positive; namely, $\mu>0$; and when the increased demand caused by the increasing customization degree is lower than the decreased demand caused by the increasing price, the change rate of demand will be negative; namely, $\mu<0$. But only when $\mu>0$, it will be a feasible solution for the MCLS.

Proof. When $\mu<0$, the increased demand caused by the increasing customization degree is lower than the decreased demand caused by the increasing price. According to the assumption (3), it is assumed that the unit price of the product $P_{1}$ is constant; hence, in this condition, if choosing the MCLS, the profit of the LSI and the customer will be lower than choosing the complete large-scale logistics service (see Appendix A for a detailed proof).

Hence, considering the LSI and the customer pursuing the maximum profit, when $\mu<0$, both of them will not choose the MCLS. Therefore, $\mu<0$ would not be taken into consideration and later studies would focus on the condition where $\mu \geq 0$.

3.2.2. The Profit Function of the LSI. The profit of the LSI is the difference between its total income and total cost, it can be expressed as follows:

$$
\pi_{1}=P Q-C Q
$$

Substituting (1), (3), and (4) into (8), the profit function of the LSI will turn to

$$
\begin{aligned}
\pi_{1}= & -\left[C_{1} \omega+C_{2} t(-1+\beta)\right] \\
& \times\left[-a-Q_{0} t+b\left(C_{1}+C_{1} \omega+C_{2} t \beta\right)\right] .
\end{aligned}
$$

In order to determine the optimal customization degree that can maximize the profit of the LSI, the first-order and the second-order derivative of $\pi_{1}$ on $t$ are calculated as follows. Consider

$$
\begin{aligned}
& \frac{\partial \pi_{1}}{\partial t}=Q_{0} {\left[C_{1} \omega+2 C_{2} t(-1+\beta)\right]+a C_{2}(-1+\beta) } \\
&+b C_{2}\left[-2 C_{2} t(-1+\beta) \beta+C_{1}(1+\omega-\beta-2 \omega \beta)\right] \\
& \frac{\partial^{2} \pi_{1}}{\partial t^{2}}=2 C_{2}(-1+\beta)\left(Q_{0}-b C_{2} \beta\right) .
\end{aligned}
$$

As $\mu=Q_{0}-b C_{2} \beta \geq 0$ (seen in Theorem 1 ) and $\partial^{2} \pi_{1} / \partial t^{2}$ $<0$, hence the function $\pi_{1}$ is strictly convex function on $t(-\infty,+\infty)$.

Therefore, to optimize profit of the LSI, $\partial \pi_{1} / \partial t=0$ should be required in first-order condition, resulting in $t_{1}=$ $\left(C_{1} \omega\left[Q_{0}-b C_{2} \beta\right]-C_{2}(1-\beta)\left[a-b C_{1}(1+\omega)\right]\right) /\left(2 C_{2}(1-\beta)\left(Q_{0}-\right.\right.$ $\left.\left.b C_{2} \beta\right)\right)$.

In the mathematical calculation, $t_{1}$ can be all the real numbers. It is the point which can make (9) maximum. But in this paper it is the customization degree factor, so it should be positive.

As $t_{1} \in(-\infty,+\infty)$ in this situation, it should be carefully discussed to limit $t \in(0,+\infty)$.

(1) When $t_{1}>0$, on $[0,+\infty)$, at first the function of $\pi_{1}$ monotonically increases, then it monotonically decreases. When $t=t_{1}$, the LSI gets the maximum profit, and the maximum profit is

$$
\pi_{1}^{\prime}=\frac{\left[C_{1}\left[-Q_{0} \omega+b C_{2}(1+\omega-\beta)\right]+a C_{2}(-1+\beta)\right]^{2}}{4 C_{2}(-1+\beta)\left(-Q_{0}+b C_{2} \beta\right)} .
$$

(2) When $t_{1} \leq 0$, on $[0,+\infty)$, the function of $\pi_{1}$ monotonically decreases. When $t_{1}=0$; namely, the SLI provides complete large-scale service to customer; the LSI will get the maximum profit. Hence, in this condition the SLI will refuse to provide MCLS to customer.

Therefore, in order to ensure the LSI provides MCLS to customer, it should be ensured that $t_{1}>0$. And obviously $C_{2}$ is a function of $t_{1}$, so it can be assumed that

$$
\begin{aligned}
t_{1} & =f_{1}\left(C_{2}\right) \\
& =\frac{C_{1} \omega\left[Q_{0}-b C_{2} \beta\right]-C_{2}(1-\beta)\left[a-b C_{1}(1+\omega)\right]}{2 C_{2}(1-\beta)\left(Q_{0}-b C_{2} \beta\right)} .
\end{aligned}
$$

Then it only needs to ensure $f_{1}\left(C_{2}\right)>0$.

3.2.3. The Profit Function of the LSI. According to the description of the model, when the customer received the products which uses the MCLS, he will sell these products to the product customers to gain the profits. Hence, the profit of the customer is the difference between his total income and total cost as follows:

$$
\pi_{2}=P_{1} Q-\left(P+P_{0}\right) Q
$$


Substituting (1) and (4) into (13), the profit function of the customer will become

$$
\begin{aligned}
\pi_{2}= & {\left[P_{0}-P_{1}+C_{1}(1+\omega)+C_{2} t \beta\right] } \\
& \times\left[-a-Q_{0} t+b\left[C_{1}(1+\omega)+C_{2} t \beta\right]\right] .
\end{aligned}
$$

To further study the impact of the customization degree on customer service profit and determine the optimal customization degree that can maximize the profit of the customer, the first-order and the second-order derivative of $\pi_{2}$ on $t$ are presented as follows:

$$
\begin{gathered}
\frac{\partial \pi_{2}}{\partial t}=\left(-Q_{0}+b C_{2} \beta\right)\left[P_{0}-P_{1}+C_{1}(1+\omega)+C_{2} t \beta\right] \\
+C_{2} \beta\left[-a-Q_{0} t+b\left[C_{1}(1+\omega)+C_{2} t \beta\right]\right] \\
\frac{\partial^{2} \pi_{2}}{\partial t^{2}}=2 C_{2} \beta\left(-Q_{0}+b C_{2} \beta\right) .
\end{gathered}
$$

From Theorem 1, $\mu=Q_{0}-b C_{2} \beta \geq 0$ and $0<\beta<1$, so $\partial^{2} \pi_{2} / \partial t^{2}<0$ can be obtained; hence the function $\pi_{2}$ is strictly convex function on $t(-\infty,+\infty)$.

Therefore, finding the optimal profit of the customer only requires first-order condition $\partial \pi_{2} / \partial t=0$. After some calculation, $t_{2}$ could be obtained as follows:

$$
\begin{aligned}
t_{2}= & \left(\left[\left(P_{0}-P_{1}\right)+C_{1}(1+\omega)\right]\left(Q_{0}-b C_{2} \beta\right)\right. \\
& \left.+C_{2} \beta\left[a-b C_{1}(1+\omega)\right]\right) \\
\times & \left(2 C_{2} \beta\left(-Q_{0}+b C_{2} \beta\right)\right)^{-1} .
\end{aligned}
$$

Similar to the LSI, in the mathematical calculation, $t_{2}$ can be all the real numbers. It is the point which can make (14) maximum. But in this paper it is the customization degree factor, so it should be positive, and thus it should be limited as $t \in(0,+\infty)$.

(1) When $t_{2}>0$, on $[0,+\infty)$, at first the function of $\pi_{2}$ monotonically increases, then it monotonically decreases. When $t=t_{2}$, the customer gets the maximum profit, and the maximum profit is

$$
\begin{aligned}
\pi_{2}^{\prime}= & -\left(\left[-P_{1} Q_{0}+C_{1} Q_{0}(1+\omega)-a C_{2} \beta\right.\right. \\
& \left.\left.+b C_{2} P_{1} \beta+P_{0}\left(Q_{0}-b C_{2} \beta\right)\right]^{2}\right) \\
& \times\left(4 C_{2} \beta\left(-Q_{0}+b C_{2} \beta\right)\right)^{-1} .
\end{aligned}
$$

(2) When $t_{2} \leq 0$, on $[0,+\infty)$, the function of $\pi_{2}$ monotonically decreases; that is, with the increase of the customization degree, customer profit will gradually decrease. When $t_{2}=0$, namely, when the customer receives complete large-scale service, the customer will get the maximum profit. Hence, in this condition the customer will refuse to choose MCLS.
Therefore, to ensure that the customer chooses MCLS, $t_{2}>0$ should be guaranteed. And obviously $C_{2}$ is a function of $t_{2}$, so it could be assumed that

$$
\begin{aligned}
t_{2} & =f_{2}\left(C_{2}\right) \\
& =\frac{C_{1} \omega\left[Q_{0}-b C_{2} \beta\right]-C_{2}(1-\beta)\left[a-b C_{1}(1+\omega)\right]}{2 C_{2}(1-\beta)\left(Q_{0}-b C_{2} \beta\right)} .
\end{aligned}
$$

Then it only needs to ensure $f_{2}\left(C_{2}\right)>0$.

Considering the conditions that the LSI provides the MCLS and the customer chooses the MCLS, Theorem 3 could be obtained.

Theorem 3. Only when $C_{2}<\min \left\{C_{1} \omega \mu /(1-\beta) Q_{1},\left[P_{1}-P_{0}-\right.\right.$ $\left.\left.C_{1}(1+\omega)\right] \mu / \beta Q_{1}\right\}$, the LSI and the customer will cooperate with MCLS.

Proof. In order to ensure that both LSI and the customer choose the MCLS, $f_{1}\left(C_{2}\right)>0$ and $f_{2}\left(C_{2}\right)>0$ must be guaranteed. As $f_{1}\left(C_{2}\right)>0, C_{2}<C_{1} \omega \mu /(1-\beta) Q_{1}$. And $f_{2}\left(C_{2}\right)>0, C_{2}<\left[P_{1}-P_{0}-C_{1}(1+\omega)\right] \mu / \beta Q_{1}$. Therefore when $C_{2}<\min \left\{C_{1} \omega \mu /(1-\beta) Q_{1},\left[P_{1}-P_{0}-C_{1}(1+\omega)\right] \mu / \beta Q_{1}\right\}$, that is, the unit increased cost compared with complete largescale logistics service is less than a certain value, the LSI and the customer would likely cooperate with MCLS.

\section{The Analysis of the Customization Degree in Three Different Decision Modes}

From Section 3, it has been found that the customization degree factors which can maximize the profit of LSI and customer are different. Therefore, in order to determine the customization degree that can satisfy the LSI and the customer coordination could be taken into consideration. In this section, three different decision modes are considered: customization degree dominated by LSI (Case A), customization degree dominated by customer (Case B), and customization degree decided by concentrated supply chain (Case C). And we will explore the effect of different decision modes on optimal customization degree factor and put forward the optimal customization degree decision model based on the profit secondary distribution strategy.

4.1. The Customization Degree Dominated by LSI. As a leader in the coordination of the supply chain, the LSI will provide logistics service to customer with the customization degree factor $t_{1}$, which can maximize his profit. And the customer has to cooperate with the LSI at $t=t_{1}$. In this case, the customization degree factor is

$$
\begin{aligned}
t^{\text {caseA }} & =t_{1} \\
& =\frac{C_{1} \omega\left[Q_{0}-b C_{2} \beta\right]-C_{2}(1-\beta)\left[a-b C_{1}(1+\omega)\right]}{2 C_{2}(1-\beta)\left(Q_{0}-b C_{2} \beta\right)} .
\end{aligned}
$$


The profit of the LSI is

$$
\pi_{1}^{\text {caseA }}=\frac{\left[C_{1}\left[-Q_{0} \omega+b C_{2}(1+\omega-\beta)\right]+a C_{2}(-1+\beta)\right]^{2}}{4 C_{2}(-1+\beta)\left(-Q_{0}+b C_{2} \beta\right)} .
$$

The profit of the customer is

$$
\begin{aligned}
& \pi_{2}^{\text {caseA }} \\
& =\left(C_{1}\left[\left[Q_{0} \omega-b C_{2}(1+\omega-\beta)\right]+a C_{2}(1-\beta)\right]\right. \\
& *\left[(-1+\beta)\left[2\left(Q_{0}-b C_{2} \beta\right)\left(P_{1}-P_{0}\right)+a C_{2} \beta\right]\right. \\
& \quad-C_{1}\left[b \beta C_{2}(1+\omega-\beta)-2(1+\omega) Q_{0}\right. \\
& \left.\left.\left.+\beta(2+\omega) Q_{0}\right]\right]\right) \\
& \quad \times\left(4 C_{2}(-1+\beta)^{2}\left(-Q_{0}+b C_{2} \beta\right)\right)^{-1} .
\end{aligned}
$$

The profit of whole supply chain is $\pi_{T}^{\text {caseA }}=\pi_{1}^{\text {caseA }}+\pi_{2}^{\text {caseA }}$.

4.2. The Customization Degree Dominated by Customer. When the customization degree is dominated by customer, the customer will choose logistics service with the customization degree factor $t_{2}$, which can maximize his profit. And the LSI has to cooperate with the customer at $t=t_{2}$. In this case, the customization degree factor is

$$
\begin{aligned}
t^{\text {caseB }}= & t_{2} \\
= & \left(\left[\left(P_{0}-P_{1}\right)+C_{1}(1+\omega)\right]\left(Q_{0}-b C_{2} \beta\right)\right. \\
& \left.\quad+C_{2} \beta\left[a-b C_{1}(1+\omega)\right]\right) \\
& \quad \times\left(2 C_{2} \beta\left(-Q_{0}+b C_{2} \beta\right)\right)^{-1} .
\end{aligned}
$$

The profit of the LSI is

$$
\begin{aligned}
& \pi_{1}^{\text {caseB }} \\
& =\left(\left[-P_{1} Q_{0}+C_{1} Q_{0}(1+\omega)-a C_{2} \beta\right.\right. \\
& \left.+b C_{2} P_{1} \beta+P_{0}\left(Q_{0}-b C_{2} \beta\right)\right] \\
& \text { * }\left[(-1+\beta)\left[\left(Q_{0}-b C_{2} \beta\right)\left(P_{1}-P_{0}\right)-a C_{2} \beta\right]\right. \\
& \left.\left.+C_{1}\left[2 b C_{2} \beta(-1-\omega+\beta)+Q_{0}(1+\omega-\beta+\omega \beta)\right]\right]\right) \\
& \times\left(4 C_{2} \beta^{2}\left(-Q_{0}+b C_{2} \beta\right)\right)^{-1} \text {. }
\end{aligned}
$$

The profit of the customer is

$$
\begin{aligned}
\pi_{2}^{\text {caseB }}=-( & -P_{1} Q_{0}+C_{1} Q_{0}(1+\omega)-a C_{2} \beta \\
& \left.\left.+b C_{2} P_{1} \beta+P_{0}\left(Q_{0}-b C_{2} \beta\right)\right]^{2}\right) \\
& \times\left(4 C_{2} \beta\left(-Q_{0}+b C_{2} \beta\right)\right)^{-1} .
\end{aligned}
$$

The profit of whole supply chain is $\pi_{T}^{\text {caseB }}=\pi_{1}^{\text {caseB }}+\pi_{2}^{\text {caseB }}$.
4.3. The Customization Degree Decided by Concentrated Supply Chain. In this case, the LSI and the customer form a joint venture to achieve the goal of optimizing the supply chain as a whole. The total profit of the whole supply chain is the difference between the LSI and the customer's total income and total cost. That is

$$
\pi_{T}=P_{1} Q-\left(P_{0}+C\right) Q .
$$

Substituting (1) and (3) into (25), the profit function of the supply chain will become

$$
\begin{aligned}
\pi_{T}= & \left(P_{1}-C_{1}-P_{0}-C_{2} t\right) \\
& \times\left[a+Q_{0} t-b\left[C_{1}(1+\omega)+C_{2} t \beta\right]\right] .
\end{aligned}
$$

To further study the impact of the customization degree on the profit of the whole supply chain, take the first-order and the second-order derivative of $\pi_{T}$ versus $t$; then

$$
\begin{aligned}
\frac{\partial \pi_{T}}{\partial t}= & -a C_{2}-Q_{0}\left(C_{1}+P_{0}-P_{1}+2 C_{2} t\right) \\
& +b C_{2}\left[\left(P_{0}-P_{1}+2 C_{2} t\right) \beta+C_{1}(1+\omega+\beta)\right], \\
& \frac{\partial^{2} \pi_{T}}{\partial t^{2}}=2 C_{2}\left(-Q_{0}+b C_{2} \beta\right)=-2 C_{2} \mu .
\end{aligned}
$$

Let $\partial \pi_{T} / \partial t=0$; then $t_{3}=\left(C_{2}\left[a-b C_{1}(1+\omega)\right]+\left(P_{0}-P_{1}+\right.\right.$ $\left.\left.C_{1}\right)\left[Q_{0}-b C_{2} \beta\right]\right) /\left(-2 C_{2}\left(Q_{0}-b C_{2} \beta\right)\right)$.

Similar to the above, in the mathematical calculation, $t_{3}$ can be all the real numbers. It is the point which can make (26) maximum. But in this paper it is the customization degree factor, so it should be positive.

From Theorem 1, it could be known that $\mu=Q_{0}-b C_{2} \beta \geq$ 0 , so $\partial^{2} \pi_{T} / \partial t^{2}<0$. According to Theorem 3 , if the LSI and the customer cooperate together, it should be ensured that $f_{1}\left(C_{2}\right)>0, f_{2}\left(C_{2}\right)>0$. According to these conclusions, it can be proved that $t_{3}>0$ (seen in the Appendix B). Hence the function $\pi_{T}$ is strictly convex function on $t(0,+\infty)$. At last, the whole supply chain will get its maximal profit when $t=t_{3}$, and the maximal profit is

$$
\begin{aligned}
\pi_{T}^{\prime}= & \left(\left[-a C_{2}+\left(C_{1}+P_{0}-P_{1}\right) Q_{0}\right.\right. \\
& \left.\left.+b C_{2}\left[C_{1}(1+\omega)+\beta\left(P_{1}-C_{1}-P_{0}\right)\right]\right]^{2}\right) \\
& \times\left(4 C_{2}\left(Q_{0}-b C_{2} \beta\right)\right)^{-1} .
\end{aligned}
$$

In the LSSC with centralized decision mode, the target is to get the maximal profit of the whole supply chain. So in this case, the customization degree factor is

$$
\begin{aligned}
t^{\mathrm{caseC}}= & t_{3} \\
= & \left(C_{2}\left[a-b C_{1}(1+\omega)\right]\right. \\
& \left.\quad+\left(P_{0}-P_{1}+C_{1}\right)\left[Q_{0}-b C_{2} \beta\right]\right) \\
& \times\left(-2 C_{2}\left(Q_{0}-b C_{2} \beta\right)\right)^{-1} .
\end{aligned}
$$


The profit of the LSI is

$$
\begin{aligned}
& \pi_{1}^{\text {caseC }} \\
& =\left(\left[a C_{2}-b C_{1} C_{2}(1+\omega)+\left(Q_{0}+b C_{2} \beta\right)\left(P_{1}-P_{0}-C_{1}\right)\right]\right. \\
& *\left[a C_{2}(-1+\beta)-Q_{0}\left[2 C_{1} \omega+(-1+\beta)\left(P_{1}-C_{1}-P_{0}\right)\right]\right. \\
& +b C_{2}\left[\left(P_{1}-P_{0}\right)(-1+\beta) \beta\right. \\
& \left.\left.\left.+C_{1}(1+\omega-\beta)(1+\beta)\right]\right]\right) \\
& \times\left(4 C_{2}\left(-Q_{0}+b C_{2} \beta\right)\right)^{-1} \text {. }
\end{aligned}
$$

The profit of the customer is

$$
\begin{array}{ll}
\pi_{2}^{\text {caseC }} & \\
=-\left(\left[a C_{2}-b C_{1} C_{2}(1+\omega)+\left(Q_{0}+b C_{2} \beta\right)\left(P_{1}-P_{0}-C_{1}\right)\right]\right. \\
\quad *\left[2 P_{1}\left(Q_{0}-b C_{2} \beta\right)-P_{1} \beta\left(Q_{0}-b C_{2} \beta\right)\right. \\
\quad+P_{0}(-2+\beta)\left(Q_{0}-b C_{2} \beta\right)+a C_{2} \beta \\
\left.\left.\quad+C_{1}\left[b C_{2}(1+\omega-\beta) \beta+Q_{0}(-2-2 \omega+\beta)\right]\right]\right) \\
\quad \times\left(4 C_{2}\left(-Q_{0}+b C_{2} \beta\right)\right)^{-1} .
\end{array}
$$

The profit of the whole supply chain (i.e., the centralized supply chain) is

$$
\begin{array}{ll}
\pi_{T}^{\text {caseC }} & \\
=( & {\left[-a C_{2}+\left(C_{1}+P_{0}-P_{1}\right) Q_{0}\right.} \\
& \left.\left.\quad+b C_{2}\left[C_{1}(1+\omega)+\beta\left(P_{1}-C_{1}-P_{0}\right)\right]\right]^{2}\right) \\
& \quad \times\left(4 C_{2}\left(Q_{0}-b C_{2} \beta\right)\right)^{-1} .
\end{array}
$$

Table 2 shows three optimal decision values in different decision modes. Through comparing the profit of different decision modes, Theorems 4 and 5 could be obtained as follows.

Theorem 4. The profit of the centralized supply chain is greater than that of LSSC dominated by LSI or customer.

Theorem 5. Whether LSSC is dominated by LSI or customer, the dominator will obtain more profit than he is a partner: That is to say $\pi_{1}^{\text {case } A} \geq \pi_{1}^{\text {case } C} \geq \pi_{1}^{\text {case } B}$ and $\pi_{2}^{\text {case } B} \geq \pi_{2}^{\text {caseC }} \geq \pi_{2}^{\text {case } A}$.

For more detailed proof of Theorems 4 and 5, please see the Appendices $\mathrm{C}$ and $\mathrm{D}$.

4.4. The Decision Model of Optimal Customization Degree Based on the Profit Secondary Distribution Strategy. Through calculation of Table 2 , it has been known that $\pi_{1}^{\text {caseA }} \geq$ $\pi_{1}^{\text {caseC }} \geq \pi_{1}^{\text {caseB }}$ and $\pi_{2}^{\text {caseB }} \geq \pi_{2}^{\text {caseC }} \geq \pi_{2}^{\text {caseA }}$. Obviously, the profits of the LSI or the customer are less than the profits generated in their own leading, when they carry out the cooperation mode of Case C. Neither of them have the motives to carry out the cooperation model of Case C. Therefore, it is particularly important to design a reasonable profit coordinate mechanism, which can make the LSI and the customer implement the centralized decision of mass customization LSSC. So a profit secondary distribution strategy is introduced in this section.

At first, the profit losses of the LSI and the customer is calculated when the centralized decision mode is chosen. And the profit losses of the LSI are

$$
\begin{aligned}
\Delta \pi_{1} & =\pi_{1}^{\text {caseC }}-\pi_{1}^{\text {caseA }} \\
& =-\frac{\left(Q_{0}-b C_{2} \beta\right)\left[C_{1} \omega+(1-\beta)\left(P_{0}+C_{1}-P_{1}\right)\right]^{2}}{4 C_{2}(1-\beta)} .
\end{aligned}
$$

The profit losses of the customer are

$$
\begin{aligned}
\Delta \pi_{2} & =\pi_{2}^{\text {caseC }}-\pi_{2}^{\text {caseB }} \\
& =-\frac{\left(Q_{0}-b C_{2} \beta\right)\left[\left(P_{1}-P_{0}-C_{1}\right)(1-\beta)-C_{1} \omega\right]^{2}}{4 C_{2} \beta} .
\end{aligned}
$$

Obviously, $\Delta \pi_{1}<0, \Delta \pi_{2}<0$.

A good profit coordinate mechanism is to decrease the loss as little as possible. It is necessary for us to make profit secondary distribution in order to make both of them choose a common customization degree which can maximize the profit of the whole supply chain. Assumption in the cooperative enterprise is composed of the LSI and the customer, the profit given to the LSI is $M_{1}$, the profit given to the customer is $M_{2}$, and $M_{1}+M_{2}=0$. Then according to NASH Bargaining Model, the optimization model is shown as follows:

$$
\begin{array}{ll}
\operatorname{Max} & Z=\left(\left|\Delta \pi_{1}\right|+M_{1}\right)\left(\left|\Delta \pi_{2}\right|+M_{2}\right) \\
\text { s.t. } & M_{1}+M_{2}=0 .
\end{array}
$$

With (33) and (34) substituted into (35), it could be presented as

$$
\begin{aligned}
Z= & \left(M_{1}+\frac{\left(Q_{0}-b C_{2} \beta\right)\left[C_{1} \omega+(1-\beta)\left(C_{1}+P_{0}-P_{1}\right)\right]^{2}}{4 C_{2}(1-\beta)}\right) \\
& \times\left(-M_{1}\right. \\
& \left.+\frac{\left(Q_{0}-b C_{2} \beta\right)\left[\left(P_{1}-P_{0}-C_{1}\right)(1-\beta)-C_{1} \omega\right]^{2}}{4 C_{2} \beta}\right) .
\end{aligned}
$$




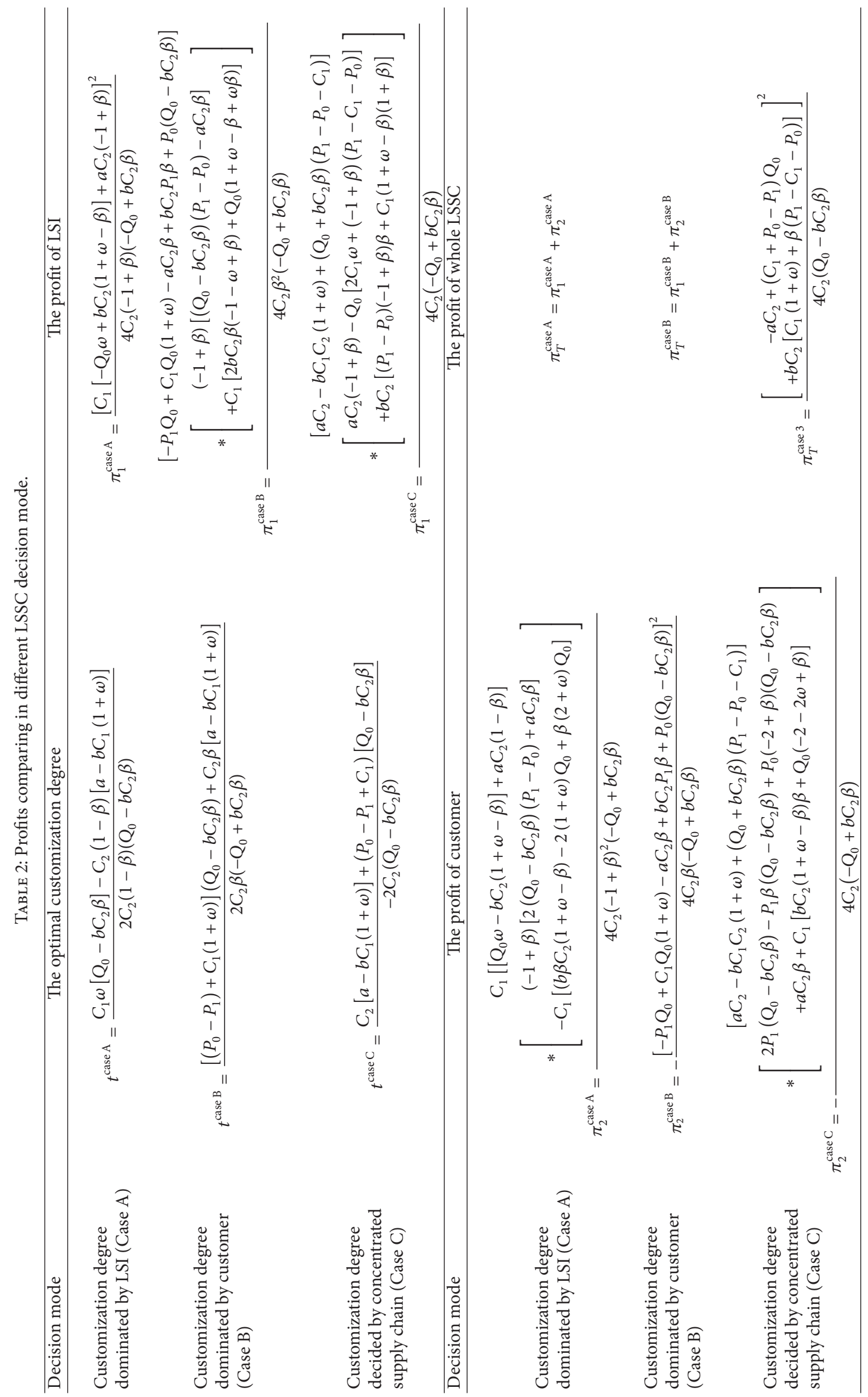


In order to determine the optimal $M_{1}$ that can maximize $Z$, take the first-order and the second-order derivative of $Z$ as follows:

$$
\begin{aligned}
& \frac{\partial Z}{\partial M_{1}} \\
& =\frac{1}{4}\left[-8 M+\left((-1+2 \beta)\left(Q_{0}-b C_{2} \beta\right)\right.\right. \\
& \left.\quad \times\left[C_{1} \omega-\left(P_{1}-C_{1}-P_{0}\right)(1-\beta)\right]^{2}\right) \\
& \left.\times\left(C_{2}(1-\beta) \beta\right)^{-1}\right] ; \\
& \frac{\partial^{2} Z}{\partial M_{1}^{2}}=-2 .
\end{aligned}
$$

Let $\partial Z / \partial M_{1}=0$; then

$$
\begin{aligned}
M_{1}= & \left((-1+2 \beta)\left(Q_{0}-b C_{2} \beta\right)\right. \\
& \left.\times\left[C_{1} \omega-\left(P_{1}-C_{1}-P_{0}\right)(1-\beta)\right]^{2}\right) \\
& \times\left(8 C_{2}(1-\beta) \beta\right)^{-1} .
\end{aligned}
$$

Obviously, $M_{1}=(-1+2 \beta)\left(Q_{0}-b C_{2} \beta\right)\left[C_{1} \omega-\left(P_{1}-\right.\right.$ $\left.\left.C_{1}-P_{0}\right)(1-\beta)\right]^{2} / 8 C_{2}(1-\beta) \beta$ is the optimal $M_{1}$ which can maximize $Z$.

Therefore, $M_{1}=(-1+2 \beta)\left(Q_{0}-b C_{2} \beta\right)\left[C_{1} \omega-\left(P_{1}-\right.\right.$ $\left.\left.C_{1}-P_{0}\right)(1-\beta)\right]^{2} / 8 C_{2}(1-\beta) \beta ; M_{2}=-(-1+2 \beta)\left(Q_{0}-\right.$ $\left.b C_{2} \beta\right)\left[C_{1} \omega-\left(P_{1}-C_{1}-P_{0}\right)(1-\beta)\right]^{2} / 8 C_{2}(1-\beta) \beta$.

Hence, the customization degree factor is $t^{\text {caseC }}$ which eventually both of them agreed. And finally, the profit of the LSI is $\pi_{1}^{\text {caseC }}+M_{1}$ and the profit of the customer is $\pi_{2}^{\text {caseC }}+M_{2}$. Then, substituting $t^{\text {caseC }}$ into $t=\gamma /(1-\gamma)$, the optimal customization degree is found where $\gamma=t^{\text {caseC }} /\left(1+t^{\text {caseC }}\right)$.

\section{Numerical Analysis}

In Section 5, in order to verify some of the theorems put forward above, numerical analysis is conducted by the software of Matlab 8.0 for numerical calculation. In Section 5.1, how the profits of the LSI and the customer change with the customization degree factor $t$ is discussed. In Section 5.2, in different decision modes, how the optimal customized degree factor and the profits (such as the LSI's profit, the customer's profit and the total profit of LSI and customer) change would be discussed. The parameters in numerical analysis are as follows: $C_{1}=50, \omega=0.3, \beta=0.8, a=1000, b=10, Q_{0}=20$, $P_{0}=1000, P_{1}=1200$.

5.1. The Change of LSI's Profit and Customer's Profit with the Changing oft. First of all, the range of the unit increased cost $C_{2}$ is figured out. As the case that the change rate of demand is greater than zero is considered, $\mu=Q_{0}-b C_{2} \beta>0$ should be ensured. From Theorem 3, if the LSI and the customer both choose MCLS, it need $\mathrm{f}_{1}\left(\mathrm{C}_{2}\right)>0$ and $\mathrm{f}_{2}\left(\mathrm{C}_{2}\right)>0$. Substituting them into (12) and (18), $C_{2}<1.58$ is easily obtained.

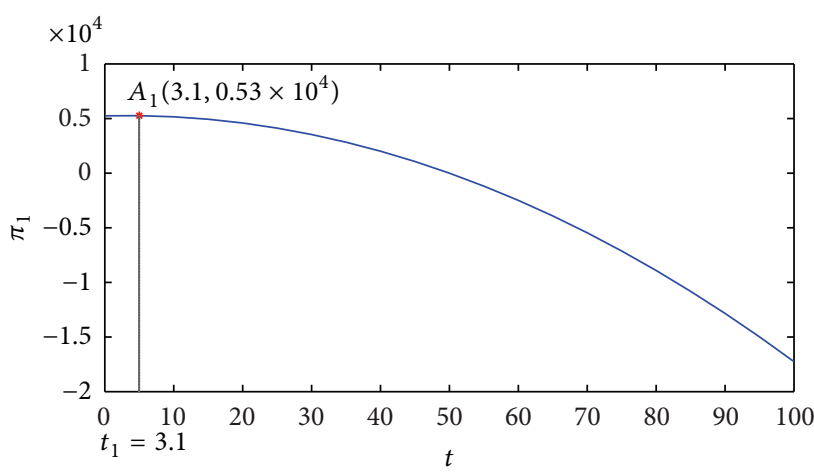

Figure 2: The change of the LSI's profit with $t$, when $C_{2}=1.5$.

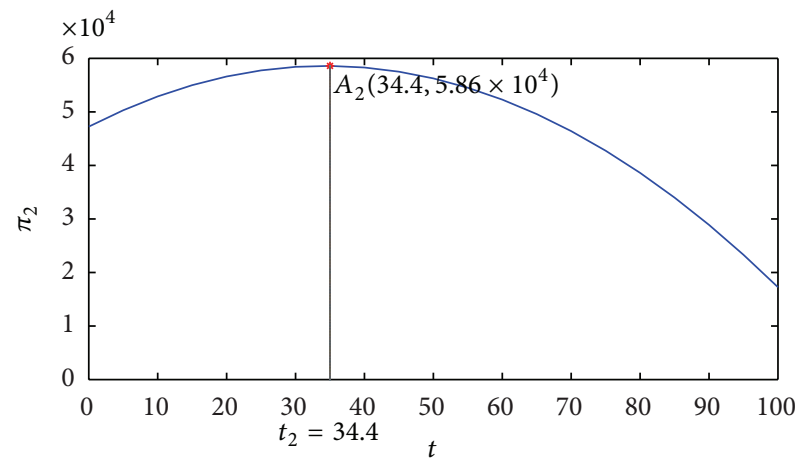

FIGURE 3: The change of the customer's profit with $t$, when $C_{2}=1.5$.

When the unit increased cost $C_{2}$ is set as a certain value, the change of LSI's profit and customer's profit with $t$ is shown in Figures 2 and 3.

From Figures 2 and 3 , it can be seen that point $A_{1}, A_{2}$ is the highest point of the curve, respectively. Obviously, at first, the profit of LSI and customer increases and then it will decrease with the increase of customization degree factor $t$. Thus the customization degree should not be too high, and a reasonable customization degree can ensure that the LSI and the customer achieve maximum profit. In addition, when $t=$ $t_{1}$, the LSI achieves the maximum profit, but when $t=t_{2}$, the customer achieves the maximum profit, and $t_{1}<t_{2}$. So the LSI and the customer can not realize optimal synchronously. Therefore, it is necessary to coordinate the customization degree of service between the LSI and the customer.

5.2. The Change of the Profit of the LSI and the Customer in Three Different Decision Modes. In order to further explore the impact of the customization degree on the profit and the best way to coordinate, the unit increased cost $C_{2}$ is chosen as $1.57,1.5,1.3,1.1, \ldots, 0.5,0.3,0.1,0.01$, respectively; then study how the LSI's profit, the customer's profit, and the total profit of LSI and customer change in different decision modes. Detailed results are shown in Tables 3, 4, and 5.

From Table 3, when customization degree is dominated by LSI, along with the decrease of the unit increased cost, the customization degree factor of the LSI is gradually increasing, and the profit of the LSI and the customer will also increase. 
TABLE 3: The optimal customization degree factor and the optimal profit when the customization degree is dominated by LSI.

\begin{tabular}{lcccc}
\hline$C_{2}$ & $t^{\text {case A }}$ & $\pi_{T}^{\text {case A }}$ & $\pi_{1}^{\text {case A }}$ & $\pi_{2}^{\text {case A }}$ \\
\hline 1.57 & 0.4 & 52704.6 & 5250.3 & 47454.3 \\
1.5 & 3.1 & 54492.2 & 5273.4 & 49218.8 \\
1.3 & 10.6 & 61550.9 & 5531.3 & 56019.6 \\
1.1 & 18.5 & 72212.4 & 6090.2 & 66122.2 \\
0.9 & 28.0 & 88403.4 & 7055.7 & 81347.7 \\
0.7 & 41.4 & 114524.5 & 8708.5 & 105816.0 \\
0.5 & 64.1 & 162207.4 & 11816.4 & 150391.0 \\
0.3 & 115.1 & 274272.4 & 19229.4 & 255043.0 \\
0.1 & 365.9 & 836409.9 & 56656.9 & 779753.0 \\
0.01 & 3741.2 & 8432878.0 & 562878.0 & 7870000.0 \\
\hline
\end{tabular}

Because $C_{2}<1.58$, a close result $C_{2}=1.57$ as the upper limit of the analysis is applied in this table.

TABLE 4: The optimal customization degree factor and the optimal profit when the customization degree is dominated by customer.

\begin{tabular}{lcccc}
\hline$C_{2}$ & $t^{\text {case B }}$ & $\pi_{T}^{\text {case B }}$ & $\pi_{1}^{\text {case B }}$ & $\pi_{2}^{\text {case B }}$ \\
\hline 1.57 & 30.2 & 58952.1 & 3167.8 & 55784.3 \\
1.5 & 34.4 & 61523.4 & 2929.7 & 58593.7 \\
1.3 & 46.7 & 71286.6 & 2286.2 & 69000.4 \\
1.1 & 61.1 & 85635.7 & 1615.8 & 84019.9 \\
0.9 & 80.1 & 107153.7 & 805.7 & 106348.0 \\
0.7 & 108.4 & 141645.3 & -331.7 & 141977.0 \\
0.5 & 157.8 & 204394.9 & -2246.1 & 206641.0 \\
0.3 & 271.3 & 351616.2 & -6551.8 & 358168.0 \\
0.1 & 834.6 & 1089532.0 & -27718.1 & 1117250.0 \\
0.01 & 8428.7 & 11056187.0 & -312513.0 & 11368700.0 \\
\hline
\end{tabular}

Because $C_{2}<1.58$, a close result $C_{2}=1.57$ as the upper limit of the analysis is applied in this table.

But when $C_{2}$ takes the same value, comparing $\pi_{T}^{\text {caseA }}$ in Table 3 with $\pi_{T}^{\text {caseC }}$ in Table 5 , the total profit of the LSI and the customer is still lower than the LSSC with centralized decision mode. Therefore this decision mode is not the optimal.

From Table 4, when customization degree is dominated by customer, along with the decrease of the unit increased cost, the customization degree factor expected by the customer will increase and the profit of the customer also will increase; however, the profit of the LSI will decrease, even to be negative. Comparing $\pi_{T}^{\text {caseB }}$ in Table 4 with $\pi_{T}^{\text {caseC }}$ in Table 5, it can be found that the total profit of the LSI and the customer is still lower than that in the LSSC with centralized decision mode. Therefore the decision mode dominated by the customer is not the optimal.

From Table 5, when the customization degree is decided by concentrated supply chain, if secondary distribution strategy is applied, along with the decreasing of the unit increased cost, the customization degree factor will increase gradually, and the profit of the LSI $\pi_{\text {last } 1}$ and the profit of the customer $\pi_{\text {last2 }}$ will increase. In addition, comparing Tables 3,4 , and 5, some other conclusions have been found.
(1) When the customization degree is decided by concentrated supply chain, the total profit of the LSI and the customer ( $\pi_{T}^{\text {caseC }}$ in Table 5 ) is higher than that dominated by the LSI ( $\pi_{T}^{\text {caseA }}$ in Table 3 ) or the customer $\left(\pi_{T}^{\text {caseB }}\right.$ in Table 4$)$. So Theorem 4 is proved. At the same time it shows that the LSSC with centralized decision mode is the best coordination strategy. And the customization degree factor is optimal in this case.

(2) When the customization degree is dominated by LSI, the profit of the LSI ( $\pi_{1}^{\text {caseA }}$ in Table 3 ) is greater than that dominated by customer $\left(\pi_{1}^{\text {caseB }}\right.$ in Table 4$)$, and it is also greater than that decided by concentrated supply chain ( $\pi_{1}^{\text {caseC }}$ in Table 5$)$. And when the customer is dominating the decision mode, the profit of the customer is greater than that in the LSI dominating $\left(\pi_{2}^{\text {caseA }}\right.$ in Table 3$)$, and it is also greater than that in the LSSC with centralized decision mode $\left(\pi_{2}^{\text {caseC }}\right.$ in Table 5). Hence, the Theorem 5 is proved.

(3) In addition, it is found that $t^{\text {caseC }}$ is between $t^{\text {caseA }}$ and $t^{\text {caseB }}$. And after applying secondary distribution strategy, the profit of the LSI $\pi_{1}^{\prime}$ and the profit of customer $\pi_{2}^{\prime}$ are lower than the profit generated in the modes dominated by themselves, respectively, but higher than the profit generated in the mode dominated by the partner. And the loss of profit is minimum, compared with those dominated by themselves.

\section{Conclusions and Future Works}

6.1. Main Conclusions. While a LSSC with mass customization service is considered, this paper discussed the coordination issue of customization degree between the LSI and the customer. First, demand function of the customer for logistics services is built, and on this basis, the LSI and the customer's profit function is provided. And then three different decision modes about customization degree are presented. After that, in different decision modes, how the profit of the LSI, custome, and the overall supply chain changes with the customization degree is analyzed in detail. The main conclusions are listed as follows.

(1) The total demand of customer for logistics service is influenced by both the price and the customization degree. And it will increase with the increase of customization degree, but with the increase of price, it will decrease.

(2) When the increased demand caused by the increasing customization degree is higher than the decreased demand caused by the increasing price, the change rate of demand will be positive; and when the increased demand caused by the increasing customization degree is lower than the decreased demand caused by the increasing price, the change rate of demand will be negative.

(3) To achieve MCLS cooperation between the LSI and the customer, the LSI should make the unit increase 
TABLE 5: The optimal customization degree factor and profit when the customization degree decided by concentrated supply chain, after applying secondary distribution strategy.

\begin{tabular}{lcccccccc}
\hline$C_{2}$ & $t^{\text {case C }}$ & $\pi_{T}^{\text {case C }}$ & $\pi_{1}^{\text {case C }}$ & $\pi_{2}^{\text {case C }}$ & $M_{1}$ & $M_{2}$ & $\pi_{\text {last 1 }}$ \\
\hline 1.57 & 24.25 & 59368.6 & 3917.5 & 55451.1 & 499.8 & -499.8 & 4417.3 \\
1.5 & 28.12 & 61992.2 & 3773.4 & 58218.8 & 562.5 & -562.5 & 4335.9 & 57951.3 \\
1.3 & 39.46 & 71935.6 & 3454.4 & 68481.2 & 778.8 & -778.8 & 4233.2 \\
1.1 & 52.56 & 86530.5 & 3226.5 & 83304.0 & 1073.9 & -1073.9 & 4300.4 & 67702.4 \\
0.9 & 69.66 & 108403.7 & 3055.7 & 105348 & 1500.0 & -1500.0 & 4555.7 & 103848 \\
0.7 & 94.99 & 143452.7 & 2922.7 & 140530 & 2169.6 & -2169.6 & 5092.3 & 138360.4 \\
0.5 & 139.06 & 207207.4 & 2816.4 & 204391 & 3375.0 & -3375.0 & 6191.4 & 201016 \\
0.3 & 240.06 & 356772.4 & 2729.4 & 354043 & 6187.5 & -6187.5 & 8916.9 & 347855.5 \\
0.1 & 740.88 & 1106407 & 2656.9 & 1103750 & 20250.0 & -20250.0 & 22906.9 & 1083500 \\
0.01 & 7491.21 & 11231228 & 2628.0 & 11228600 & 210094 & -210094 & 212722 & 11018506 \\
\hline
\end{tabular}

Because $C_{2}<1.58$, a close result $C_{2}=1.57$ as the upper limit of the analysis is applied in this table.

cost of the customized logistics services lower than a certain value; that is, $C_{2}<\min \left\{C_{1} \omega \mu /(1-\beta) Q_{1}\right.$, $\left[P_{1}-\right.$ $\left.\left.P_{0}-C_{1}(1+\omega)\right] \mu / \beta Q_{1}\right\}$.

(4) Whoever dominates the customization degree realizes more profit than as a participator in decentralized LSSC or as partner in centralized LSSC.

(5) In the LSSC with centralized decision mode, the profit of the whole supply chain is greater than decentralized decision mode. And a profits secondary distribution strategy could be used to obtain maximum profit which is the same as the profit of LSSC with centralized decision mode.

6.2. Research Limitations and Future Work. There are some limitations in the profit model of the LSI and the customer. For example, it is assumed that the unit price of the product $P_{1}$ is determined by market as a constant value. However, when the product is sensitive to time, the greater the customization degree of logistics service is (e.g., the product delivery time is shorter), the higher the price of the product will be. Therefore, the decision model of variable $P_{1}$ could be considered in future research. In addition, to simplify the model, LSI's cost is divided into two parts, that is, the largescale service cost and the customization service cost in this paper. However, with the varying of customization degree, the peculiar monitoring cost of customized logistics service may be changed. These problems need to be explored in detail in future research.

\section{Appendices}

\section{A. Proof That When $\mu<0$, Choosing the MCLS, the Profit of the LSI and the Customer Will Be Lower Than Choosing the Complete Large-Scale Logistics Service}

Proof. when the customer chooses complete large-scale logistics service, the customization degree factor is 0 ; that is, $t=0$. In this case, with $t=0$ substituted into (9), the profit of the LSI can be obtained as $\pi_{1}^{t=0}=C_{1} \omega\left[a-b C_{1}(1+\omega)\right]$ and with $t=0$ substituted into (14), the profit of the customer can be obtained as $\pi_{2}^{t=0}=\left[P_{1}-P_{0}-C_{1}(1+\omega)\right]\left[a-b C_{1}(1+\omega)\right]$.

When the customer chooses mass customization logistics service, according to (9), the profit of the LSI can be obtained as $\pi_{1}=\left[C_{1} \omega+C_{2} t(-1+\beta)\right]\left[a-b C_{1}(1+\omega)+\mu t\right]$. According to (14), the profit of the customer can be obtained as

$$
\pi_{2}=\left[P_{1}-P_{0}-C_{1}(1+\omega)-C_{2} t \beta\right]\left[a-b C_{1}(1+\omega)+\mu t\right] .
$$

By comparison, when $\mu<0$, we can get $a-b C_{1}(1+\omega)+$ $\mu t<a-b C_{1}(1+\omega)$. And because of $0<\beta<1$, we can get $C_{1} \omega+C_{2} t(-1+\beta)<C_{1} \omega, P_{1}-P_{0}-C_{1}(1+\omega)-C_{2} t \beta<$ $P_{1}-P_{0}-C_{1}(1+\omega)$. Hence, $\pi_{1}<\pi_{1}^{t=0}$ and $\pi_{2}<\pi_{2}^{t=0}$ can be obtained.

In conclusion, when $\mu<0$, the LSI and the customer that choose mass customization logistics service will get lower profit than choosing complete large-scale logistics service.

\section{B. Under the Conditions of $f_{1}\left(C_{2}\right)>0, f_{2}\left(C_{2}\right)>0$, Then $t_{3}>0$}

Proof. Because that change rate of demand is expressed as $\mu=$ $Q_{0}-b C_{2} \beta$ and the demand is expressed as $Q_{1}=a-b C_{1}(1+\omega)$ when the LSI provide mass customization logistics service for the customer, $f_{1}\left(C_{2}\right), f_{2}\left(C_{2}\right), t_{3}$ can be changed as follows:

$$
\begin{aligned}
f_{1}\left(C_{2}\right)= & t_{1} \\
= & \frac{C_{1} \omega\left[Q_{0}-b C_{2} \beta\right]-C_{2}(1-\beta)\left[a-b C_{1}(1+\omega)\right]}{2 C_{2}(1-\beta)\left(Q_{0}-b C_{2} \beta\right)} \\
= & \frac{C_{1} \omega \mu-C_{2}(1-\beta) Q_{1}}{2 C_{2}(1-\beta) \mu}, \\
f_{2}\left(C_{2}\right)= & t_{2} \\
= & \left(\left[\left(P_{0}-P_{1}\right)+C_{1}(1+\omega)\right]\left(Q_{0}-b C_{2} \beta\right)\right. \\
& \left.\quad+C_{2} \beta\left[a-b C_{1}(1+\omega)\right]\right)
\end{aligned}
$$




$$
\begin{gathered}
\quad \times\left(2 C_{2} \beta\left(-Q_{0}+b C_{2} \beta\right)\right)^{-1} \\
=\frac{\left[\left(P_{0}-P_{1}\right)+C_{1}(1+\omega)\right] \mu+C_{2} \beta Q_{1}}{-2 C_{2} \beta \mu}, \\
t_{3}=\left(C_{2}\left[a-b C_{1}(1+\omega)\right]\right. \\
\left.\quad+\left(P_{0}-P_{1}+C_{1}\right)\left[Q_{0}-b C_{2} \beta\right]\right) \\
\quad \times\left(-2 C_{2}\left(Q_{0}-b C_{2} \beta\right)\right)^{-1} \\
=\frac{C_{2} Q_{1}+\left(P_{0}-P_{1}+C_{1}\right) \mu}{-2 C_{2} \mu} \\
=\frac{Q_{1}}{-2 \mu}+\frac{P_{1}-P_{0}-C_{1}}{2 C_{2}} .
\end{gathered}
$$

According to $f_{1}\left(C_{2}\right)>0$, we can get $C_{1} \omega / C_{2}>(1-$ $\beta) Q_{1} / \mu$; and according to $f_{2}\left(C_{2}\right)>0$, we can get $\left[P_{1}-P_{0}-\right.$ $\left.C_{1}(1+\omega)\right] / C_{2}>\beta Q_{1} / \mu$. So $\left(P_{1}-P_{0}-C_{1}\right) / C_{2}>Q_{1} / \mu$, if both left and right sides of the two formulae above are added up respectively. Then when can get $\left(P_{1}-P_{0}-C_{1}\right) / 2 C_{2}>Q_{1} / 2 \mu$, hence $t_{3}>0$.

\section{The Proof of Theorem 4}

Proof. Subtract the whole profit of supply chain in two conditions that the LSI dominates the decision mode and the customer dominates the decision mode, respectively, from the whole profit of supply chain in the LSSC with centralized decision mode.

We can get

$$
\begin{aligned}
& \pi_{T}^{\text {case3 }}-\pi_{T}^{\text {case } 1} \\
& \quad=\frac{\left(Q_{0}-b C_{2} \beta\right)\left[\left(P_{1}-P_{0}\right)(1-\beta)+C_{1}(-1-\omega+\beta)\right]^{2}}{4 C_{2}(-1+\beta)^{2}} ; \\
& \pi_{T}^{\text {case3 }}-\pi_{T}^{\text {case2 }} \\
& \quad=\frac{\left(Q_{0}-b C_{2} \beta\right)\left[\left(P_{1}-P_{0}\right)(1-\beta)+C_{1}(-1-\omega+\beta)\right]^{2}}{4 C_{2} \beta^{2}} .
\end{aligned}
$$

Because of the change rate of demand is $\mu=Q_{0}-b C_{2} \beta>$ 0 and the remaining items are all greater than 0 obviously, $\pi_{T}^{\text {case } 3}-\pi_{T}^{\text {case } 1}>0$ and $\pi_{T}^{\text {case } 3}-\pi_{T}^{\text {case } 1}>0$ can be obtained. By the methods of subtraction and comparison, the conclusion that the whole profit of supply chain in the LSSC with centralized decision mode is greater than the whole profit of supply chain in the condition that the LSI dominates the decision mode or the customer dominate the decision mode.

\section{The Proof of Theorem 5}

Proof. Firstly, compare the profit of the LSI in different decision modes:

$$
\begin{aligned}
& \pi_{1}^{\text {case1 }}-\pi_{1}^{\text {case2 }} \\
& =\frac{\left(Q_{0}-b C_{2} \beta\right)\left[C_{1} \omega+(1-\beta)\left(C_{1}+P_{0}-P_{1}\right)\right]^{2}}{4 C_{2}(1-\beta) \beta^{2}} ;
\end{aligned}
$$

$$
\begin{aligned}
& \pi_{1}^{\text {case } 1}-\pi_{1}^{\text {case3 }} \\
& =\frac{\left(Q_{0}-b C_{2} \beta\right)\left[C_{1} \omega+(1-\beta)\left(C_{1}+P_{0}-P_{1}\right)\right]^{2}}{4 C_{2}(1-\beta)} .
\end{aligned}
$$

Because of change rate of demand $\mu=Q_{0}-b C_{2} \beta>0,0<$ $\beta<1$ and the remaining items all obviously greater than 0 , $\pi_{1}^{\text {case } 1}-\pi_{1}^{\text {case } 2}>0, \pi_{1}^{\text {casel }}-\pi_{1}^{\text {case } 3}>0$ can be obtained. The profit of the LSI is greater when the LSI as a leader in the coordination of supply Chain rather than the customer as a leader or in the LSSC with centralized decision mode.

Then, compare the profit of the customer in different coordination modes. Consider

$$
\begin{aligned}
& \pi_{2}^{\text {case2 }}-\pi_{2}^{\text {case } 1} \\
& =\frac{\left(Q_{0}-b C_{2} \beta\right)\left[\left(P_{1}-P_{0}-C_{1}\right)(1-\beta)-C_{1} \omega\right]^{2}}{4 C_{2}(1-\beta)^{2} \beta} ; \\
& \pi_{2}^{\text {case2 }}-\pi_{2}^{\text {case } 3} \\
& =\frac{\left(Q_{0}-b C_{2} \beta\right)\left[\left(P_{1}-P_{0}-C_{1}\right)(1-\beta)-C_{1} \omega\right]^{2}}{4 C_{2} \beta} .
\end{aligned}
$$

Because change rate of demand $\mu=Q_{0}-b C_{2} \beta>0,0<$ $\beta<1$ and the remaining items all obviously greater than 0 , $\pi_{2}^{\text {case2 }}-\pi_{2}^{\text {case1 }}>0, \pi_{2}^{\text {case } 2}-\pi_{2}^{\text {case3 }}>0$ can be obtained, the profit of the customer is greater when the customer is a leader in the coordination of supply Chain rather than the LSI as a leader or in the LSSC with centralized decision mode.

Above all, a conclusion can be obtained that whoever dominates the customization degree realizes greater profit than the partner and also greater than the LSSC with centralized decision.

\section{Conflict of Interests}

The authors declare that there is no conflict of interests regarding the publication of this paper.

\section{Acknowledgment}

This research is supported by the National Natural Science Foundation of China (Grant number 71372156), supported by Humanity and Social Science Youth foundation of Ministry of Education of China (Grant number 2013YJC630098), and sponsored by China State Scholarship Fund and Independent Innovation Foundation of Tianjin University. The reviewers' comments are also highly appreciated.

\section{References}

[1] C. Chandra and J. Grabis, "Managing logistics for mass customization: the new production frontier," in Proceedings of the 6th Biannual World Automation Congress-Image Processing, Biomedicine, Multimedia, Financial Engineering and Manufacturing-International Forum on Multimedia Image Processing (WAC '04), pp. 335-340, Seville, Spain, July 2004. 
[2] K. L. Choy, C.-L. Li, S. C. K. So, H. Lau, S. K. Kwok, and D. W. K. Leung, "Managing uncertainty in logistics service supply chain," International Journal of Risk Assessment and Management, vol. 7, no. 1, pp. 19-43, 2007.

[3] L. Wei-hua, X. Xue-cai, R. Zheng-xu, and P. Yan, "An emergency order allocation model based on multi-provider in two-echelon logistics service supply chain," Supply Chain Management, vol. 16, no. 6, pp. 391-400, 2011.

[4] L. Zhou, H. J. Lian, and J. H. Ji, "An analysis of customized level on mass customization," Journal of System \& Management, vol. 16, no. 6, pp. 685-689, 2007.

[5] G. da Silveira, D. Borenstein, and F. S. Fogliatto, "Mass customization: literature review and research directions," International Journal of Production Economics, vol. 72, no. 1, pp. 1-13, 2001.

[6] A. Bardakci and J. Whitelock, "Mass-customization in marketing: the consumer perspective," Journal of Consumer Marketing, vol. 20 , no. 5 , pp. 463-479, 2003.

[7] H. Cavusoglu, H. Cavusoglu, and S. Raghunathan, "Selecting a customization strategy under competition: mass customization, targeted mass customization, and product proliferation," IEEE Transactions on Engineering Management, vol. 54, no. 1, pp. 1228, 2007.

[8] H.-J. Lian and J.-H. Ji, "Analysis of customized level on mass customization," Journal of Shanghai Jiaotong University, vol. 40, no. 4, pp. 677-680, 2006.

[9] S. Sami Spahi, Optimizing the level of customization for products in mass customization systems [Ph.D. thesis], The University of Central Florida, Orlando, Fla, USA, 2008.

[10] Z. Xu, Q. B. Liu, and L. Chen, "Customization tactics and the measurement model of customization degree based on attribute importance," China Journal of Management, vol. 9, no. 2, pp. 296-302, 2012.

[11] C. Chandra and A. K. Kamrani, Mass Customization: A Supply Chain Approach, Kluwer Academic/Plenum, New York, NY, USA, 2004.

[12] W. Liu, Y. Yang, X. Li, H. Xu, and D. Xie, "A time scheduling model of logistics service supply chain with mass customized logistics service," Discrete Dynamics in Nature and Society, vol. 2012, Article ID 482978, 18 pages, 2012.

[13] W. Liu, H. Xu, X. Sun, Y. Yang, and Y. Mo, “Order allocation research of logistics service supply chain with mass customization logistics service," Mathematical Problems in Engineering, vol. 2013, Article ID 957260, 13 pages, 2013.

[14] W. Liu, Y. Mo, Y. Yang, and Z. Ye, "Decision model of customer order decoupling point on multiple customer demands in logistics service supply chain," Production Planning \& Control: The Management of Operations, 2014.

[15] A. M. Fiore, S.-E. Lee, and G. Kunz, "Individual differences, motivations, and willingness to use a mass customization option for fashion products," European Journal of Marketing, vol. 38, no. 7, pp. 835-849, 2004.

[16] F. Salvador, P. M. de Holan, and F. Piller, "Cracking the code of mass customization," MIT Sloan Management Review, vol. 50, no. 3, pp. 71-78, 2009.

[17] R. I. Mcintosh, J. Matthews, G. Mullineux, and A. J. Medland, "Late customisation: issues of mass customisation in the food industry," International Journal of Production Research, vol. 48, no. 6, pp. 1557-1574, 2010.

[18] J. Partanen and H. Haapasalo, "Fast production for order fulfillment: implementing mass customization in electronics industry," International Journal of Production Economics, vol. 90, no. 2, pp. 213-222, 2004.

[19] R. F. Lu, T. D. Petersen, and R. L. Storch, "Asynchronous stochastic learning curve effects in engineering-to-order customisation processes," International Journal of Production Research, vol. 47, no. 5, pp. 1309-1329, 2009.

[20] M. Comstock, K. Johansen, and M. Winroth, "From mass production to mass customization: enabling perspectives from the Swedish mobile telephone industry," Production Planning and Control, vol. 15, no. 4, pp. 362-372, 2004.

[21] F. S. Fogliatto, G. J. C. da Silveira, and D. Borenstein, "The mass customization decade: an updated review of the literature," International Journal of Production Economics, vol. 138, no. 1, pp. 14-25, 2012.

[22] L. Liang and J. Zhou, "The optimization of customized level based on mass customization," Chinese Journal of Management Science, vol. 10, no. 6, pp. 59-65, 2002.

[23] C. J. Li and H. Cheng, "The optimization analysis of customization degree under MC paradigm," Industrial Engineering and Management, no. 1, pp. 6-9, 2006.

[24] S.-T. Wang, "An analysis of manufacturers'supply and demand uncertainty based on the dynamic customisation degree," International Journal of Production Research, vol. 49, no. 10, pp. 30233043, 2011.

[25] S.-T. Wang and M.-H. Li, "Analysis of cost models and quantification models of customisation degree after VMI strategy implemented in different industries," International Journal of Manufacturing Technology and Management, vol. 26, no. 1-4, pp. 161-175, 2012.

[26] R. I. van Hoek, "The role of third-party logistics providers in mass customization," International Journal of Logistics Management, vol. 11, no. 1, pp. 37-46, 2000.

[27] L. L. Koste and M. K. Malhotra, "A theoretical framework for analyzing the dimensions of manufacturing flexibility," Journal of Operations Management, vol. 18, no. 1, pp. 75-93, 1999.

[28] R. R. Lummus, L. K. Duclos, and R. J. Vokur, "Supply chain flexibility: building a new model," Global Journal of Flexible Systems Management, vol. 4, no. 4, pp. 1-14, 2003. 


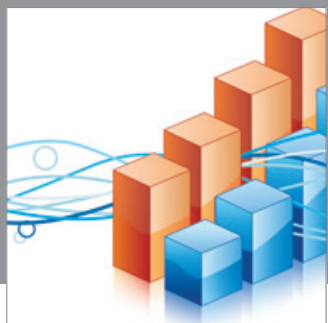

Advances in

Operations Research

mansans

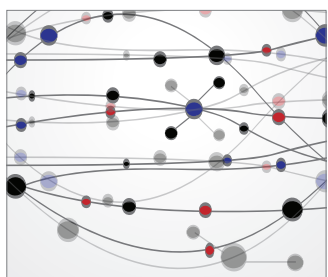

The Scientific World Journal
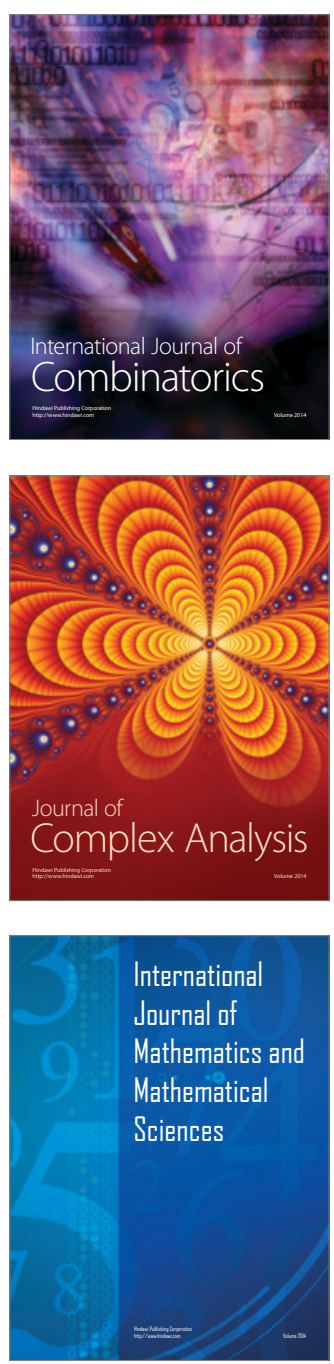
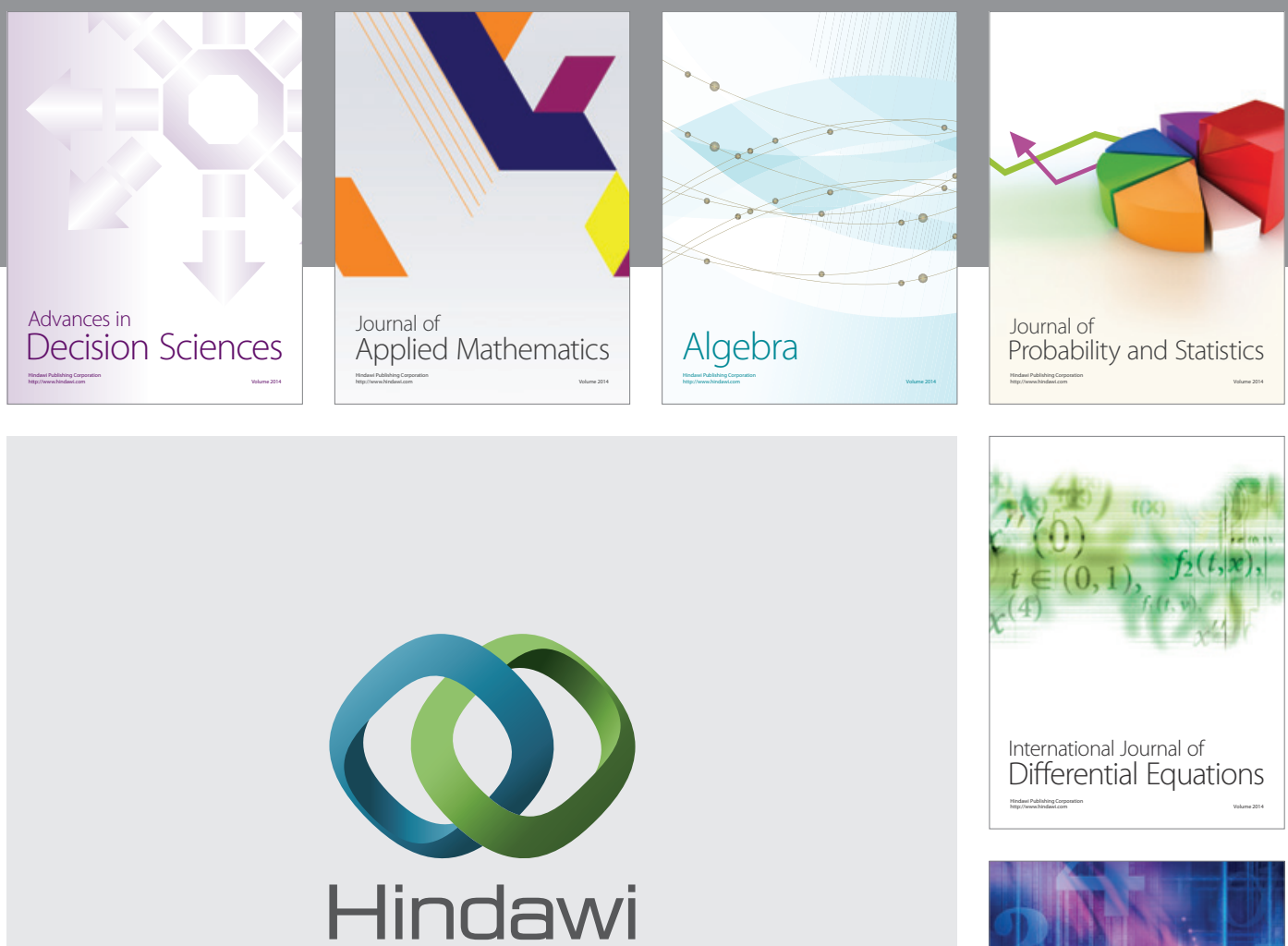

Submit your manuscripts at http://www.hindawi.com
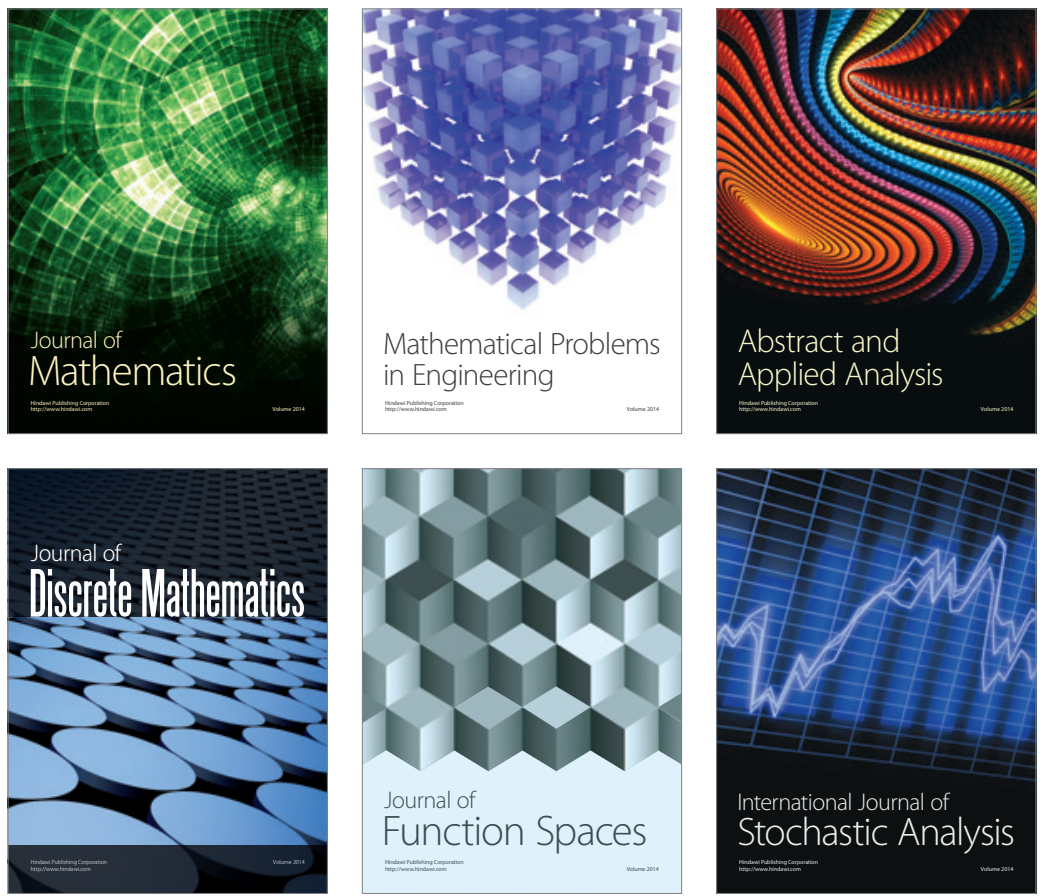

Journal of

Function Spaces

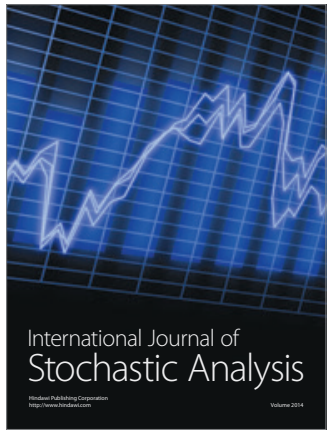

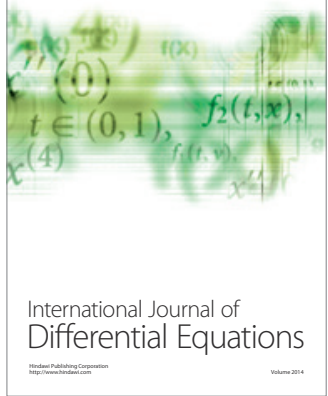
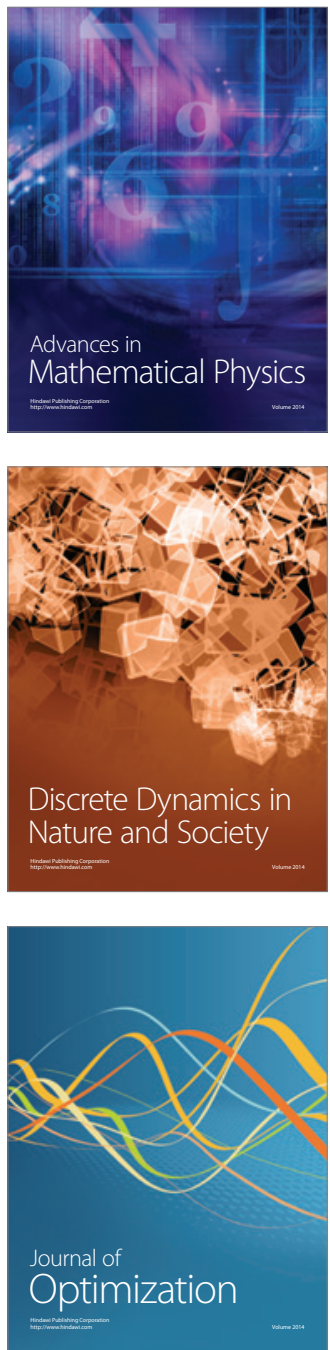